\title{
EXPLORING THE POTENTIAL OF AUGMENTED REALITY IN ENGLISH FOR REPORT WRITING: A PERCEPTIVE OVERVIEW
}

\author{
Soo Kum Yoke 1 \\ Academy of Language Studies, UiTM Cawangan Negeri Sembilan, Kampus Rembau. \\ (Email: soocarolyn@gmail.com) \\ Tuan Sarifah Aini Syed Ahmad ${ }^{2}$ \\ Academy of Language Studies, UiTM Cawangan Negeri Sembilan, Kampus Kuala Pilah. \\ (Email: tsyaini@gmail.com) \\ Nor Haniza Hasan ${ }^{3}$ \\ Academy of Language Studies, UiTM Cawangan Negeri Sembilan, Kampus Rembau. \\ (Email: haniza.071972@gmail.com)
}

Received date: $21-08-2019$

Revised date: 25-09-2019

Accepted date: $30-09-2019$

Published date: 15-12-2019

To cite this document: Soo, K. Y., Syed Ahmad, T. S. A., \& Hasan, N. H. (2019). Exploring the Potential of Augmented Reality in English for Report Writing: A Perceptive Overview. International Journal of Education, Psychology and Counseling, 4 (33), 13-21.

DOI: $10.35631 /$ IJEPC.433002

\begin{abstract}
The use of augmented reality $(A R)$ in education has changed the landscape of teaching and learning in the 21 st century. AR has changed the presentation of learning materials that allows learning activities to be more interactive and rich in multimedia. AR has the potential to increase students' engagement and motivation in learning. As such, it was incorporated in the design and development of a book for learning Report Writing. This study aims to examine students' perception of the use of AR in the language classroom, identify the lecturers' perception of the use of AR, and determine the advantages and disadvantages of the use of AR for the language classroom. The sample comprised 10 students and 7 lecturers from University Teknologi MARA Cawangan Negeri Sembilan. The data were analysed by using descriptive analysis. The findings indicate that the integration of AR in the Report Writing book had more advantages than disadvantages. The findings also suggest that integrating AR in the book had positive impacts not only in learning but also in permitting the production of a portable and environment-friendly book.
\end{abstract}

Keywords: Augmented Reality, English Language, Report Writing, Technology

\section{Introduction}

Technology has a major influence in education of the $21^{\text {st }}$ century. It promotes active learning and motivates students to learn. This leads to an active process of learning. However, the problem with technology is that when it is used in a capacity where critical thinking and metacognition is not promoted, it creates passive learning (Saidin, Abd Halim \& Yahaya, 
2015). Thus, the use of Augmented Reality (AR) has been shown to have great potential in making the learning process more effective and meaningful.

Augmented Reality (AR) is a fairly new technology in the field of education. It has the opportunity to be a disruptive technology in the delivery of educational materials. Further, AR as a teaching tool is able to provide a blended learning experience from the use of both virtual and real environments (Barrow, Forker, Sands, O'Hare \& Hurst, 2019). As such, it enhances the learning experience. Singhal et al. (2012) asserts that technology makes learning more inspiring, motivating, meaningful and remarkable for students. E-reading materials can really enhance learning among ESL learners (Soo et al., 2018). In effect, Chang et al. (2010) states that AR technology which offers 3D learning content and visualization makes learning more long lasting and effective as it supports learning by means of sound, picture, writing, video and animation. In addition, Yang (2011) states that it creates a feeling of authenticity among students.

According to Siltanen (2012), AR was first used by Tom Caudell. Caudell developed a headmounted digital (HMD) visualisation system to help train technicians on the aeroplane. Today however, the technology has advanced and expensive hardware and sophisticated equipment like the HMD are no longer required (Akcayir \& Akcayir, 2017). Instead, computers and mobile phone devices can be used to create AR materials for education. Sanusi, Abdullah, Kassim and Tidjani (2018) assert that mobile augmented reality applications have gained popularity among architectural history education students in the education field. Klopfer and Squire (2008) aptly defined AR as "a situation in which a real world context is dynamically overlaid with coherent location or context sensitive virtual information" (p.205). The materials have great potential for learning in a variety of ways.

According to Azuma (1997, as cited in Solak \& Cakir, 2015), AR technology differs from other technological tools in three ways. First, it combines real world with virtual worlds. Second, it uses real-time interaction and third, it provides accurate 3D registration of virtual and real objects. Wang et at. (2013) further emphasized that the 3D objects allow pictures, writing, videos and animations to be used both separately and simultaneously.

Although the potential of AR is numerous, there are still challenges in its application in the field of education, especially in the language classroom. While some research has been done in this area of study, it is fairly new in its application. As such, this paper will focus on the following objectives: (1) to examine students' perception of the use of AR in the language classroom; (2) to identify the lecturers' perception of the use of AR; and (3) to determine the advantages and disadvantages of using AR for the language classroom.

\section{Past Literatures}

According to Diegmann, Schmidt-Kraepelin, Eynden and Basten (2015), the concept of Augmented Reality was to augment the real world by means of virtual data. It was initially used for a number of applications in the 1960s and 1970s. Tom Caudell, a researcher dealing with AR, had initiated the use of AR for the purpose of training technicians for aeroplanes. AR has since been used for the purpose of visualisation and training by many quarters. At the same time, personal computers and mobile devices have grown to become increasingly powerful. This has led to the concept of AR being used in the learning environments today by means of such devices. 
In mapping AR for the purpose of education, Yuen, Yaoyuneyong and Johnson (2011) classified five directions of AR in educational environments.

(1) Discovery-based Learning: Students are given information of a real-world place while simultaneously considering the object of interest. This is especially useful in astronomical education and historical studies.

(2) Objects Modelling: Object modelling will allow for immediate visual feedback on how an object would look like in a different setting. This is useful in architectural education.

(3) AR Books: AR books offer students 3D presentations and interactive learning experiences through AR technology. The books are augmented with the help of technological devices.

(4) Skills Training: Students can be trained to use specific skills step by step for skill training such as repair and maintenance for those studying technical skills.

(5) AR Gaming: AR games which take place in the real world can be developed with virtual information. This provides educators with highly interactive and visual forms of learning.

In investigating the role of AR technology in motivating students for a visual art course in Spain, Di Serio et al. (2013) found that students were more motivated to learn in terms of attention and satisfaction through an augmented-reality-based learning environment compared to a slide-based learning environment. It also suggested that augmented reality technology had a positive impact on the students.

Two AR tools were developed called MOBILE and HELLO to teach the English Language to Japanese students. The study showed that after a process of implementation, the technology helped to increase learners' performances in comparison to traditional teaching methods (Tan \& Lui, 2004, Liu et al., 2010).

Barreira et al. (2012) investigated the use of AR technology in the teaching of animal words in English to Portugese elementary school children aged between 7 to 9 years. The results showed that students who were exposed to AR performed better than the other students.

Mahadzir and Phung (2013) in their study on augmented reality pop-up books examined its use to motivate and support English Language learning. After a year of observation, it was found that AR pop-up books had positive impacts and increased students' academic performance.

In sum, past literatures have shown that there are variety of ways that AR can be applied to the classroom to enhance learning. In the next section of the paper, the focus will be to discuss the present research with the use of AR technology to gauge its potential in a Report Writing English Language class at the degree level.

\section{Methodology}

In this section of the study, the method applied to the study is discussed at length. This study uses descriptive analysis to help in determining that the objectives of the study are met. The purpose of the study is to explore the potential of AR technology in the language classroom by means of using a sample English for Report Writing class. To do so, the study examines the students' and lecturers' perception of the use of AR in the language classroom and the advantages and disadvantages of the usage in the language classroom.

In a class of English for Report Writing at the bachelor degree level of 15 students, 10 agreed to participate in the study. Also, 7 lecturers from the Faculty of Information Management agreed to participate for the study. As such, the total number of participants were 17. The 
students who participated in the study were all females and they were all from the Faculty of Information Technology taking their bachelor degree. They were between 21 and 22 years old. They were all computer literate and they all owned a mobile device. The lecturers who participated in the study were all from the Faculty of Information Management. Out of the 7 participants, there was 1 male lecturer and 6 female lecturers. The lecturers who participated aged between 30 to 45 years of age. Table 1 below shows the details of the participants.

Table 1. Demographics of Participants

\begin{tabular}{lll}
\hline DETAILS OF & STUDENTS & LECTURERS \\
PARTICIPANTS & & \\
\hline No. of participants & 10 & 7 \\
\hline Race & Malay & Malay \\
\hline Faculty & Information Management & Information Management \\
\hline Age & $21-22$ years old & $30-45$ years old \\
\hline Gender & 10 Females & 1 Male 6 Females \\
\hline
\end{tabular}

The AR Book for Report Writing is an AR book developed with the use of the HP Reveal Studio application. The AR book comprises video-based lecture notes with audio, text and graphics. It is made up of only a piece of paper the size of a postcard. To use the book, students simply need to install an application known as HP Reveal in their smartphone in order to scan a specific picture that is known as an aura. When the aura is scanned, the chapter/unit will be uploaded in their smartphone. Thus, the AR book is lightweight, small and portable. Since the AR book is in digital format, it saves printing cost and paper. As a result, the AR book is friendly to the environment. Most importantly, the AR book is interactive and rich in multimedia such as text, graphics and audio. The use of multimedia in learning materials has been proven effective in enhancing students' engagement and performance in learning. Moreover, the AR book permits autonomous and personalised learning as it can be accessed online. Hence, students can learn at anytime and anywhere as long as they have Internet connection and a smartphone. The AR book for learning report writing is certainly useful not only for instructors who can design and develop engaging interactive e-learning contents but also to students who can have interactive, autonomous and personalised learning materials.

The procedure for carrying out the study was by means of a set of interview questions to each of the participants. The students were exposed to the use of the AR Book for Report Writing in their EWC661 English for Report Writing class. After using the AR Book, they were asked if they could spend ten to fifteen minutes to answer some questions pertaining to the use of the book in which ten of the students agreed. The lecturers on the other hand, were given a short briefing of how to use the book. After that, a demo of how to use the book was conducted. At the end of the briefing, they were asked some questions pertaining to the book.

The answers that were collected from both the students and lecturers who participated in the study were then tabulated and analysed using descriptive analysis.

\section{Findings and Results}

In this section of the paper, the findings and results of the study are discussed. The section is divided into the students' and lecturers' perception and the advantages and disadvantages of the AR book based on their exposure. This will then help in providing a conclusion for the investigation of the potential of using AR in the language classroom. 


\section{Students' Perception Of The Use Of The AR Book}

The ten students who agreed to be interviewed provided the following information as to how they perceived the use of the AR book for Report Writing in their classroom. Table 2 provides the items and the percentages collected from their interview session.

In table 2, all the students perceived that they have never seen this technology before (100\%). Majority also found the technology interesting for learning Report Writing (90\%). Further, they found it really exciting to learn (70\%). About $30 \%$ of the participants found the AR book easy to use and carry with them, suitable to use in class and environmentally friendly. Further, 20\% commented that it is very current and up-to-date and they can learn anywhere and any place with the AR book. Another $10 \%$ stated that it is interactive as the information can be listened to as they learn. However, $20 \%$ commented that they needed time to learn how to use AR and another $10 \%$ said that it was a bit awkward using the AR book as it is different from the conventional lesson.

Table 2. Students' perception of the use of the AR Book for Report Writing

\begin{tabular}{llll}
\hline Nos. & Items & $\mathbf{N}$ & $\mathbf{\%}$ \\
\hline $\mathbf{1 .}$ & It is very current and up-to-date. & 2 & 20.00 \\
\hline 2. & It is very interesting for learning Report Writing. & 9 & 90.00 \\
\hline 3. & It is easy to use and carry with me. & 3 & 30.00 \\
\hline $\mathbf{4 .}$ & It is interactive as I can listen to learn. & 1 & 10.00 \\
\hline $\mathbf{5 .}$ & I have never seen this before. & 10 & 100.00 \\
\hline $\mathbf{6 .}$ & I am really excited to learn. & 7 & 70.00 \\
\hline $\mathbf{7 .}$ & I need time to learn how to use AR. & 2 & 20.00 \\
\hline $\mathbf{8 .}$ & $\begin{array}{l}\text { I feel a bit awkward using this because it is } \\
\text { different. }\end{array}$ & 1 & 10.00 \\
\hline 9. & It is suitable to use in class. & 3 & 30.00 \\
\hline $\mathbf{1 0}$ & I can learn anywhere at any place with AR. & 2 & 20.00 \\
\hline 11. & It is environment friendly & 3 & 30.00 \\
\hline
\end{tabular}

\section{Lecturers' Perception of The Use of The AR Book}

The lecturers were also interviewed about the use of the AR book for Report Writing. Table 3 below indicates the findings from the interview. The lecturers' perceptions show that they think that the book is practical for blended learning (62.50\%) and that they found the book to be interactive and interesting (50\%). Also, a number of lecturers commented that the book is a good and creative innovation (37.50\%) and environmentally friendly (37.50\%). About $25 \%$ of the lecturers commented that the AR book is suitable for current techno-savvy students. Further, $12.50 \%$ mentioned that use of multimedia promotes digital learning. $12.5 \%$ said they have seen AR technology before. 
Table 3. Lecturers' Perception of The Use of The AR Book for Report Writing

\begin{tabular}{llll}
\hline Nos. & Items & $\mathbf{N}$ & $\mathbf{\%}$ \\
\hline 1. & I have seen AR technology before this. & 1 & 12.50 \\
\hline 2. & The book is practical for blended learning. & 5 & 62.50 \\
\hline 3. & This is a good and creative innovation. & 3 & 37.50 \\
\hline 4. & The book is interactive and interesting. & 4 & 50.00 \\
\hline 5. & It is environment friendly & 3 & 37.50 \\
\hline 6. & Suitable for current techno-savvy students & 2 & 25.00 \\
\hline 7. & Use of multimedia promotes digital learning & 1 & 12.50 \\
\hline
\end{tabular}

\section{Students' Perception of The Advantages and Disadvantages of The Use of AR}

Students were also asked about the advantages and disadvantages of the AR book for Report Writing. The advantages and disadvantages from their viewpoint are listed down in table 4. There were some good points about the book such as lightweight, compact, saves time, saves space, portable, affordable and content is easy to understand. At the same time, there were some disadvantages highlighted by the students such as easy to lose, takes time to scan, needs to use mobile device and cannot write notes on the screen.

Table 4. Students' Perception of The Advantages and Disadvantages of the AR Book for Report Writing

\begin{tabular}{|l|l|}
\hline Advantages & Disadvantages \\
\hline Lightweight & Easy to lose \\
\hline Compact & Takes time to scan \\
\hline Saves time & Needs to use mobile device. \\
\hline Saves space & Cannot write notes \\
\hline Portable & \\
\hline Affordable & \\
\hline Content is easy to understand & \\
\hline
\end{tabular}

Lecturers' Perception on The Advantages and Disadvantages of The Use of AR

Like the students, the lecturers were also asked what they thought were the advantages and disadvantages of the use of the AR book for Report Writing. The list of their viewpoint is shown in table 5. The results showed that the lecturers found the AR Book for Report Writing saves time, provided immediate reference, reduced cost of printing, is lightweight, is less dependent on conventional textbooks, is portable, has data storage available on internet and can teach pronunciation through listening of the audio. They also commented that the disadvantages of the AR Book included that it needs a smartphone to operate, health concerns, students are less dependent on the instructor, difficult to write notes for students and that it cannot function without the access to internet. 
Table 5. Lecturers' Perception of The Advantages and Disadvantages of The AR Book for Report Writing

\begin{tabular}{|l|l|}
\hline Advantages & Disadvantages \\
\hline Saves time & Needs smartphone to operate \\
\hline Immediate reference & Health concerns \\
\hline Reduce printing cost & Less dependent on instructor \\
\hline Lightweight & Difficult to write notes \\
\hline Less dependent on conventional textbook & Needs internet to access \\
\hline Portable & \\
\hline Data storage on internet & \\
\hline $\begin{array}{l}\text { Can teach pronunciation through listening } \\
\text { the audio }\end{array}$ & \\
\hline
\end{tabular}

Thus far, the findings and results have been discussed at length. In the next section of this paper, we will consider the conclusion of the study and recommendations that can be made.

\section{Discussion and Conclusion}

The purpose of this study was to (1) to examine students' perception of the use of AR in the language classroom; (2) to identify the lecturers' perception of the use of AR; and (3) to determine the advantages and disadvantages of using AR for the language classroom. In relation to past literatures on the use of AR for education, there have been many positive remarks by researchers (Serio et al.,2013; Barreira et al., 2012; Mahadzir and Phung, 2013). The present study also provided similar findings which substantiates the potential of using augmented reality technology for enhancing language learning.

Firstly, the students' perception of the use of AR in the language classroom by means of the AR book for Report Writing were positive with all admitting that they have never seen AR technology in the form of the book and almost all saying that they found the book interesting and are more excited to learn the subject. It can therefore be concluded that the students were enthusiastic about using AR in their lessons. Being digital natives, the students who are familiar with the use of technology had little problems in adapting to the new method applied for the classroom. However, there were a few students who were apprehensive to using the new method. This is a usual transitional process until the point where students gain more confidence in using the new set of learning approach.

Secondly, it can be concluded from the findings that lecturers' also had positive perception of the use of the AR book for Report Writing. The feedback given by the lecturers showed that they found the book practical for conducting blended learning and they thought that it was interactive and interesting.

Thirdly, it was found from the findings and results that both students and lecturers who participated in the study found the use of AR more advantages. Both the students and lecturers agreed that it saves time, is portable and lightweight. For the students, they also perceived that the content was easy to understand. However, they highlighted some disadvantages for room for improvement such as they could not make notes on the screen and it was easy to lose the book which was lightweight and the size of a postcard.

The lecturers also perceived the advantages of the book such as less printing cost and content data storage on the internet. The disadvantages the commented revealed their concerns that the students would be less dependent on the lecturers and health concerns such as eye sores. 
Overall, the study showed that AR in the language classroom has great potential with the multimedia, visual, audio, animation and so forth available that could take learning to another level. However, the concerns based on the disadvantages highlighted by the students and lecturers are also valid and should be considered for further improvement. Blended learning in $21^{\text {st }}$ century has been emphasised time and again. This avenue of using AR is a practical move towards such types of learning.

The study looked at a small scale of university students and lecturers using the AR book for teaching and learning. For future research, it is recommended that a study of the use of AR be conducted at a wider scale with more measuring instruments used besides interview and discussions with the participants after the implementation session of the AR in the language classroom.

\section{References}

Akcayir, M. \& Akcayir, G. (2017). Advantages and challenges associated with augmented reality for education: A systematic review of the literature. Educational Research Review 20, 1-11.

Barreira, J., Bessa, M., Pereira, L.C., Adao, T., Peres, E., \& Magalhaes, L. (2012). MOW: Augmented Reality game to learn words in different languages. Case study: Learning English names of animals in elementary school. $7^{\text {th }}$ Iberian Conference on Information Systems and Tecnologies (CISTI), 1-6.

Barrow, J., Forker, C., Sands, A.,O'Hare, D., \& Hurst, W. (2019). Augmented Reality for Enhancing Life Science Education. Paper presented at VISUAL 2019 - The Fourth International Conference on Applications and Systems of Visual Paradigms, Rome, Italy.

Chang, G., Morreale,P. \& Medicherla, P. (2010). Applications of augmented reality systems in education. D. Gibson and B. Dodge (Eds.), Proceedings of Society for Information Technology and Teacher Education International Conference, 1380-1385. Chesapeake, VA: AACE.

Di Serio, A., Ibanez, M.B., \& Delgado-Kloos, C. (2013). Impact of an augmented reality system on students' motivation for a visual art course. Computers \& Education 68, 586596.

Diegmann, P., Schmidt-Kraepelin, M., Eynden, S., \& Rasten, D. (2015). Benefits of Augmented Reality in Educational Environments - A systematic Literature Review. Wirtschaftsinformatic Proceedings at AISeL.

Klopfer, E. \& Squire, K. (2008). Environmental Detectives - The Development of an Augmented Reality Platform for Environmental Simulations. Educational Technology Research and Development 56, 203-228.

Liu, T.T., \& Chu, Y. (2010). QR code and augmented reality-supported mobile English learning system. Mobile Multimedia Processing Lecture Notes in Computer Science, 5960, 37-52.

Mahadzir, N. \& Phung, L. (2013). The use of augmented reality pop-up book to increase motivation in English language learning for national primary school. Journal of Research \& Method in Education, (1)1, 26-38.

Saidin, N.F., Abd Halim, N.D. \& Yahaya, N. (2015). A Review of Research on Augmented Reality in Education: Advantages and Applications. International Education Studies, Vol.8, N. 13.

Sanusi, A.N.Z., Abdullah, F., Kassim, M.H., Tidjani, A.A. (2018). Architectural History Education: Students' Perception on Mobile Augmented Reality Learning Experience. Advanced Science Letters, Vol.24(11), pp.8171-8175. 
Siltanen, S. (2012). Theory and applications of marker-based augmented reality. Retrieved from http://www.vtt.fi/inf/pdf/science/2012/S3.pdf

Singhal, S., Bagga, S., Goyal, P., \& Sazena, V. (2012). Augmented chemistry: Interactive education system. International Journal of Computer Applications, 49 (15), 1-5.

Soo, K.Y., Nor Haniza Hasan, Rohani Jangga, Siti Nuur-Ila Mat Kamal \& Sofwah Mat Nawi (2018). Enhancing comprehension with e-reading materials. Insight Journal Vol.1 (1)pp.1-10.

Tan, T., \& Liu,Y. (2004). The mobile-based interactive learning environment (MOBILE) and a case study for assisting elementary school English learning. Proceedings of the IEEE International Conference on Advanced Learning Technologies.

Wang, M., Callaghan, V., Bernhardt, J., White, K. \& Pena-Rios, A. (2018). Augmented reality in education and training: pedagogical approaches and illustrative case studies. Journal of Ambient Intelligence and Humanised Computing, Vol. 9, Issue 5, pp. 1391-1402.

Yang, Y.F. (2011). Engaging students in an online situated language learning environment, Computer Assisted Language Learning, 24 (2), 181-198.

Yuen, S., Yaoyuneyong, G., \& Johnson, E. (2011). Augmented Reality: An overview and five directions for AR in Education. Journal of Educational Technology Development and Exchange 4, 119-140. 